\title{
Evaluating Environmental Impact Assessment report quality in South African national parks
}

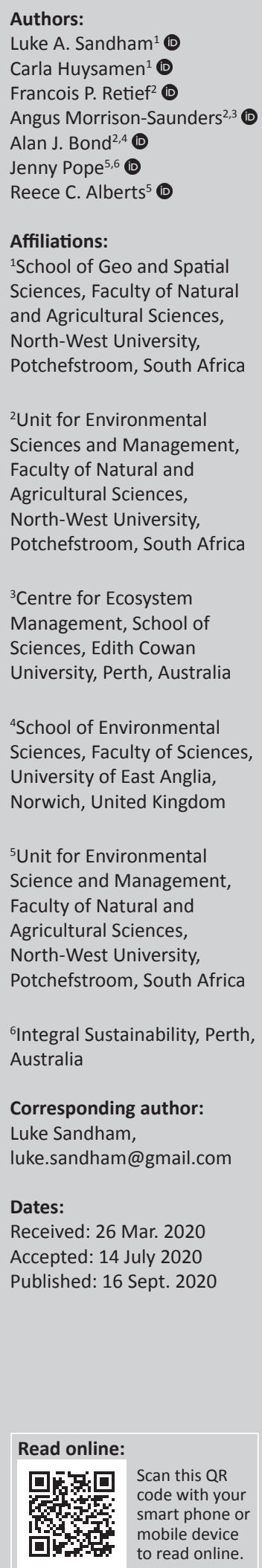

This research evaluates Environmental Impact Assessment (EIA) report quality for a selected sample of development projects in South African national parks. It applies an adapted version of an international EIA report quality review package to 24 developments within 10 national parks, across three EIA regimes. The results suggest good EIA report quality across all four quality review areas, with improvement over time, but also highlight particular weaknesses in terms of dealing with waste and, to a lesser extent, with significance and mitigation. To build on this research, the development of a sector-specific EIA report quality review package is recommended, with more emphasis on the strategic context, waste and water-related aspects. The conclusion is that EIA is well positioned to remain an important decision support instrument for developments within national parks.

Conservation implications: The results show that EIA reports for developments in South African national parks are generally of sufficient quality for decision-making that benefits conservation. However, weaker performance regarding waste, significance determination, water-related impacts and a lack of consideration of strategic context requires a conservation-specific EIA report quality review package to improve report quality in the areas of weakness and thereby increase the value of EIA as an instrument for environmental governance and sustainable development in conservation areas.

Keywords: Environmental Impact Assessment; report quality; protected areas; national parks; South Africa.

\section{Introduction}

Environmental Impact Assessment (EIA) has been conducted internationally and in South Africa since the 1970s and is recognised as one of the most successful environmental policy interventions of the 20th century (Kidd, Retief \& Alberts 2018; Morgan 2012; Roos et al. 2020). Originally conceived as an instrument to protect and conserve the biophysical environment, its mandate has since been broadened in many countries to also include the promotion of sustainable development more broadly (Cilliers et al. 2020). Today over 200 countries have some form of mandatory impact assessment system (Bond et al. 2020; Yang 2019). The overall aim of EIA is to inform decision-making by pro-actively considering and predicting consequences of actions on the environment before decisions are made (International Association for Impact Assessment and Institute of Environmental Assessment [IAIA] 1999). The actions for which mandatory EIA is required differ between countries. In South Africa, EIA is required for the so-called listed activities described in the EIA Regulations (most recently amended in 2017). Once an activity is listed, it means that actions in relation to that legally defined activity are subject to government authorisation and therefore must undergo an EIA process to inform the eventual authorisation decision.

In South Africa, infrastructure development in protected areas has been subject to mandatory EIA for more than two decades. With a rapidly increasing global population and a steadily growing middle class, protected areas are increasingly under pressure as tourist destinations (Morrison-Saunders et al. 2019; Steffen et al. 2015). Governments, especially in the global south, are understandably keen to exploit the opportunity for economic development and job creation. This is particularly true for a country such as South Africa, which boasts arguably some of the best and most diverse nature-based tourism opportunities in the world (De Witt, Van Der Merwe \& Saayman 2014). The country has a complex system of protected areas, managed by

How to cite this article: Sandham, L.A., Huysamen, C., Retief, F.P., Morrison-Saunders, A., Bond, A.J., Pope, J. et al., 2020, 'Evaluating Environmental Impact Assessment report quality in South African national parks', Koedoe 62(1), a1631. https://doi.org/10.4102/koedoe. v62i1.1631

Copyright: @ 2020 . The Authors. Licensee: AOSIS. This work is licensed under the Creative Commons Attribution License. 
agencies in the municipal, provincial and national spheres of government. However, the 21 national parks managed by the South African National Parks (SANParks) agency are the flagship of South Africa's protected areas network. With an increasing demand for tourism and tourism-related infrastructure development in protected areas, effective functioning of existing governance mechanisms aimed at planning and implementing infrastructure in a sustainable way is essential (Arrow et al. 1995; Swemmer \& Taljaard 2011). A suite of governance mechanisms for protected areas includes strategic plans, conservation plans, park management plans, species management plans and norms and standards. Many developments in protected areas in South Africa trigger mandatory EIA, and therefore, EIA is an example of an already existing governance instrument to assist with planning and implementing development in protected areas in a responsible and sustainable manner.

The output of the EIA process in South Africa is a so-called EIA report. Because the EIA report provides the basis for decisionmaking, the quality of the content of the EIA report is critical if good authorisation decisions are to be made. The underlying assumption is that good quality EIA reports enhance the likelihood of achieving good decisions (Alberts et al. 2020; Bond et al. 2016). For this reason, the quality of EIA reports has been a particular focus of international and South African EIA research (Barker \& Jones 2013; Bond et al. 2018; Jalava et al. 2010; Sandham et al. 2008a). Evaluating EIA quality should not be confused with EIA effectiveness or efficiency, which rely on good quality EIA reports in order for EIA to achieve its objectives (effectiveness) within available time and resources (efficiency) (Pope et al. 2018; Retief 2010). A wealth of literature exists on EIA report quality in South Africa for different national and regional contexts as well as for different sectors such as mining, housing, agriculture, energy and tourism (Boshoff 2019; Kidd et al. 2018; Sandham et al. 2008a, 2008b; Sandham et al. 2013b; Sandham \& Pretorius 2008; Wylie, Bhattacharjee \& Rampedi 2019). Furthermore, the quality of biodiversity specialist inputs to EIA in areas with high biodiversity value has also been researched (Hallatt, Retief \& Sandham 2015; Swanepoel et al. 2019). However, there has been scant overall reflection on the contribution of EIA to the conservation sector and more specifically protected areas.

As a first step towards gaining a better understanding of the potentially broader contribution of EIA to responsible decision making in protected areas, this research aims to evaluate the quality of EIA reports for a selected sample of developments in SANParks.

\section{Methodology}

\section{Environmental Impact Assessment report selection}

This research is concerned with EIAs for developments within the boundaries of national parks. However, SANParks does not maintain a central database for EIAs conducted in national parks, which means that an accurate representative sample cannot be identified. For this reason, it was necessary to apply the so-called replication logic that relies on a general point of saturation where the addition of more reports is unlikely to change the general patterns that emerge from the data (Yin 2003). Based on other quality review studies identified in the literature, a sample of between 20 and 30 reports is usually sufficient to reach a valid level of saturation (Hallatt et al. 2015; Sandham et al. 2013a; Swanepoel et al. 2019). Ultimately, 24 EIA reports across 10 national parks were included in this study (see Figure 1).

The 24 EIA reports included in the evaluation reflect a range of activities and development types, over different EIA regimes spanning 20 years (1997-2017) (see Table 1). To simplify the data analysis, the five periods of legal changes to the EIA legislation over the past two decades are grouped into three regime periods, namely the ECA 1997 regime, NEMA 2006/10 regime and the NEMA 2014/17 regime (see Kidd et al. 2018). Six reports reflect the ECA 1997 regime, of which two are the so-called beefed-up scoping reports ${ }^{1}$ akin to an EIA report; 10 reports reflect the NEMA 2006/10 regime; and eight reports reflect the NEMA 2014/17 regime.

\section{Environmental Impact Assessment report quality review package}

Quality review packages are widely used to evaluate the quality of EIA documentation such as scoping reports, environmental statements and specialist studies across different sectors and in different contexts (Barker \& Jones 2013; Canelas et al. 2005; Cashmore et al. 2002; Lee et al. 1999; McGrath \& Bond 1997; Sandham et al. 2008a, 2008b, 2013a; Sandham, Carrol \& Retief 2010). A package typically consists of different report quality review criteria against which the quality of EIA reports can be evaluated. The Lee and Colley review package is probably the most widely applied internationally and consists of multiple criteria arranged in a four-level hierarchical structure that consists of an overall report grade, review areas, categories and subcategories (see Figure 2; Lee et al. 1999). The Lee and Colley review package was adapted by Sandham et al. (2013a) to create a generic EIA report quality review package suitable for the South African EIA system. As the original Lee and Colley review package evaluates best practice as well as EIA report quality (Lee et al. 1999), the adapted package retained all the original Lee and Colley review topics and added a number of sub-categories to cater for the unique features of the South African EIA system. It was not deemed desirable for this research to further adapt the Sandham et al. (2013a) review package specifically for conservation or protected areas because this would have made comparison with other report quality and longitudinal ${ }^{2}$ studies difficult.

The review of an EIA report starts at the lowest level of the hierarchy, that is, the sub-categories that consist of simple criteria related to specific tasks and procedures for which grades are given. Following the review of the sub-categories, the Review Categories (RC) are evaluated,

1.Sandham and Pretorius (2008) provide an explanation of the origin and nature of 'beefed-up' scoping reports.

2.This refers to quality review studies that compare quality over time. 


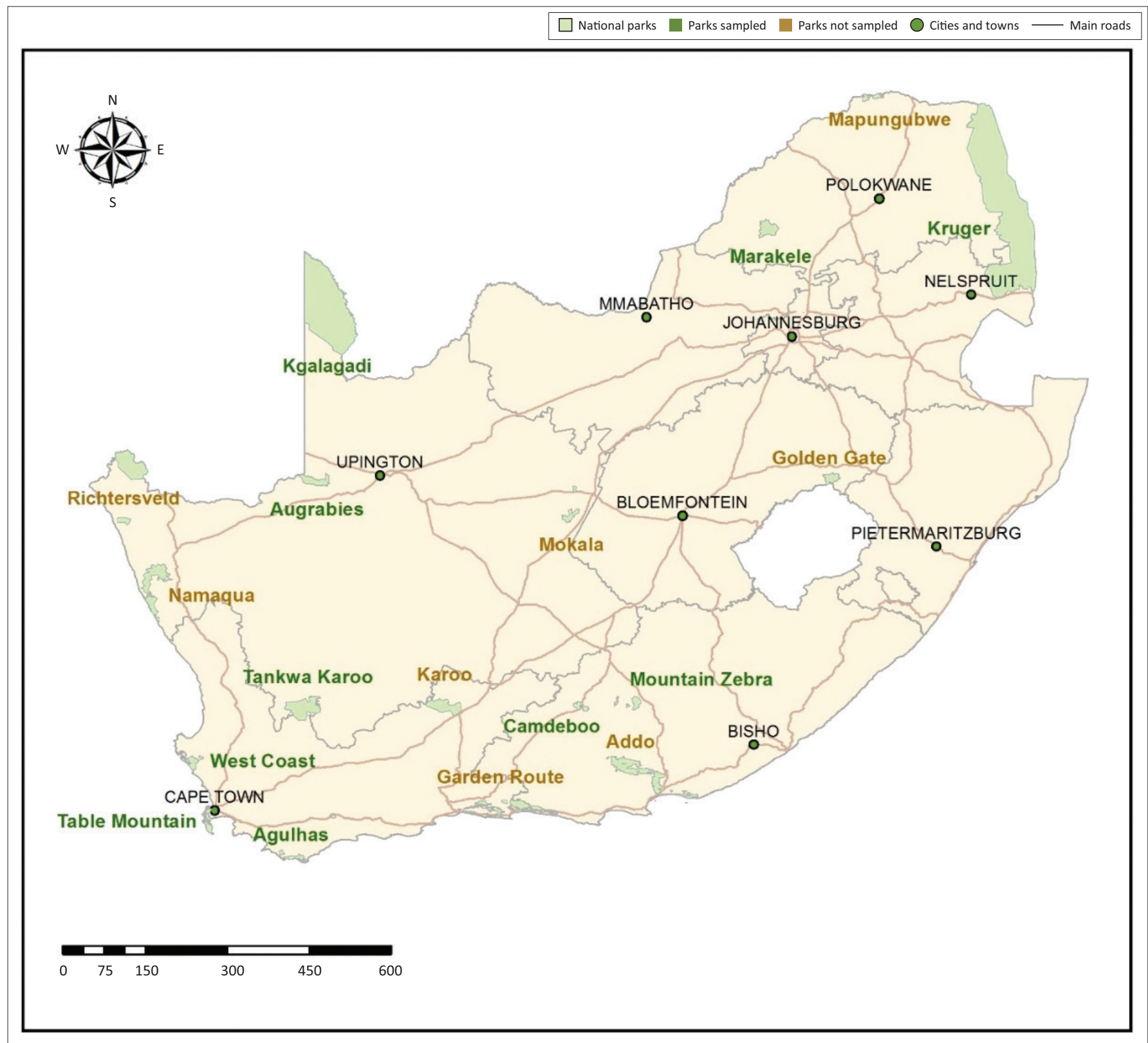

FIGURE 1: Location of national parks included in the sample of Environmental Impact Assessment reports.

followed in turn by the Review Areas (RA) and finally the overall EIA report grade. For each level, the review is based on the review grades of the previous level. A summary description of the EIA report quality review areas and criteria is provided in Table 3.

Grades are awarded ranging from A to F, depending on how well a specific task is judged by the reviewer to have been performed (Lee et al. 1999; Sandham et al. 2013a; see Table 2). The review relied on an inter-comparison and double reviewer approach to calibrate markers as recommended by Lee et al. (1999) and Põder and Lukki (2011). Two reviewers initially reviewed two of the reports independently, and the findings were recorded on a collation sheet using the assessment system of Table 2. After completing the review independently, the results were compared; differences were identified, re-examined and discussed; and a consensus was reached. Several small differences in allocated grades occurred at sub-category level, fewer at the category level, minimal differences at the level of review areas and none at the overall report level. After becoming familiar with the use of the adapted review package in the first two reports, the remaining EIA reports were then reviewed by a single reviewer.

\section{Ethical consideration}

This article followed all ethical standards for a research without direct contact with human or animal subjects.

\section{Results and discussion}

\section{Environmental Impact Assessment report} quality

Table 3 provides a summary of the overall grades, Review Area (RA) grades, Review Category (RC) and sub-category 
TABLE 1: Summary of Environmental Impact Assessment reports included in the evaluation.

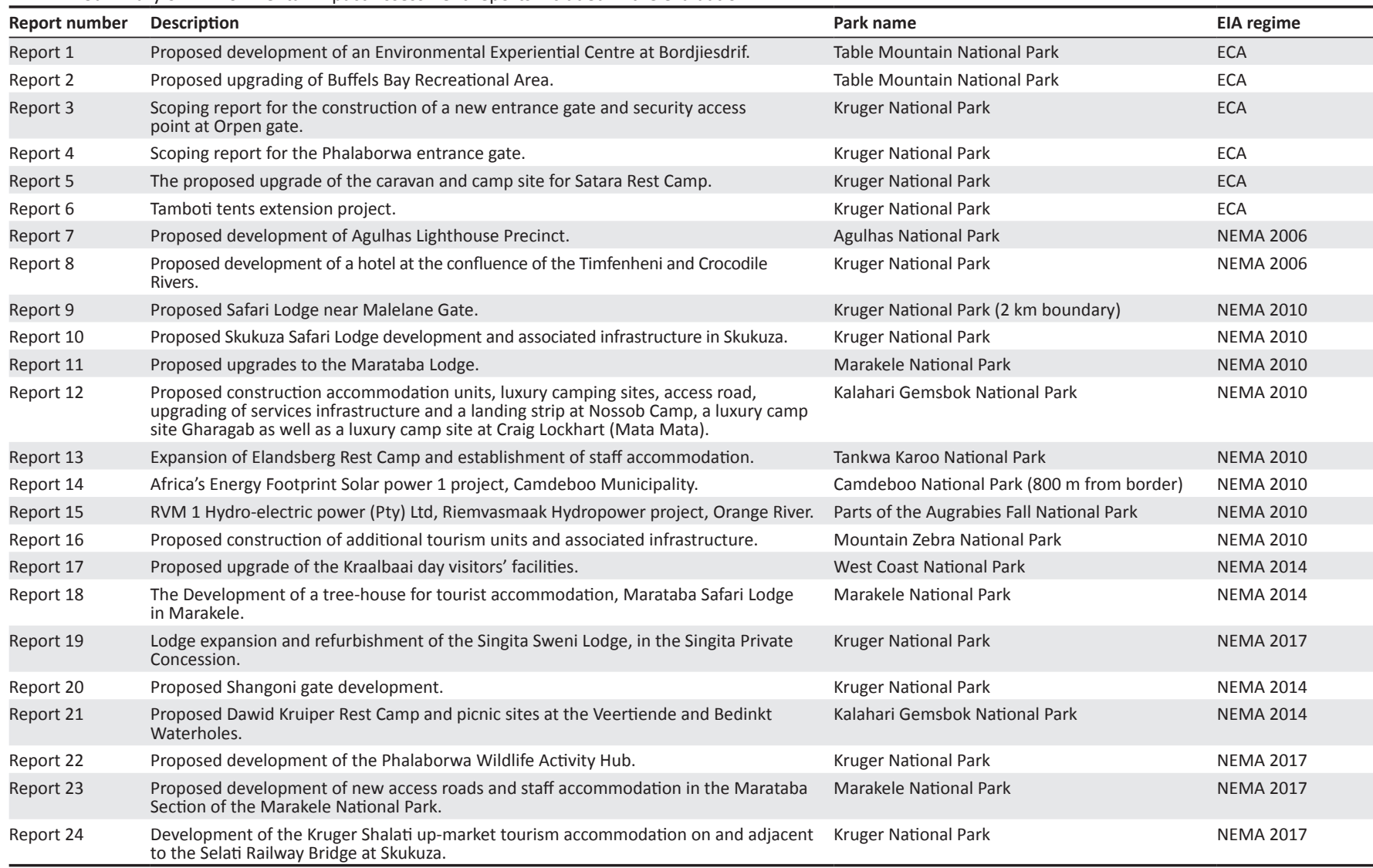

EIA, Environmental Impact Assessment; ECA, Environment Conservation Act; NEMA, National Environmental Management Act; RVM, Riemvasmaak.

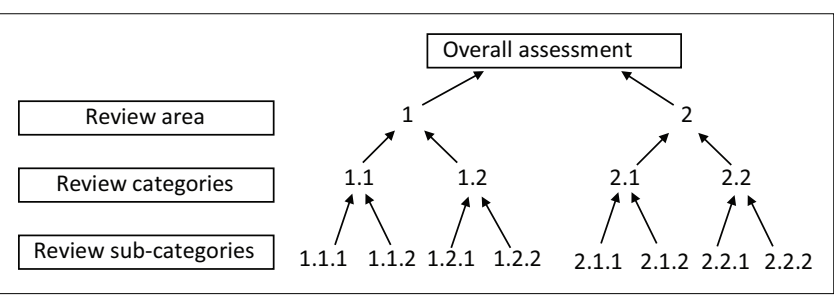

Source: Adapted from Lee, N., Colley, R., Bonde, J. \& Simpson, J., 1999, Reviewing the quality of environmental statements and environmental appraisals, Occasional paper number 55 , EIA Centre, Department of Planning and Landscape, University of Manchester, Manchester.

FIGURE 2: Hierarchical structure of the Lee and Colley Environmental Impact Assessment report review package.

TABLE 2: List of assessment symbols.

\section{Symbol Explanation}

A Relevant tasks well performed, no important tasks left incomplete.

B Generally satisfactory and complete, only minor omissions and inadequacies.

C Can be considered just satisfactory despite omissions and/or inadequacies.

D Parts are well attempted but must, as a whole, be considered just unsatisfactory because of omissions or inadequacies.

E Not satisfactory, significant omissions or inadequacies.

F Very unsatisfactory, important task(s) poorly done or not attempted.

N/A Not applicable. The review topic is not applicable, or it is irrelevant in the context of the statement.

Source: Adapted from Lee, N., Colley, R., Bonde, J. \& Simpson, J., 1999, Reviewing the quality of environmental statements and environmental appraisals, Occasional paper number 55 , EIA Centre, Department of Planning and Landscape, University of Manchester, Manchester. $\mathrm{N} / \mathrm{A}$, not applicable.

grades achieved by the 24 EIA reports, i.e. without consideration of the three different EIA regimes. The analysis of the overall quality of the EIA reports for
SANParks projects shows that $92 \%(n=22)$ of the reports were graded as satisfactory $(\mathrm{A}-\mathrm{C})$ and $25 \%(n=6)$ could be described as 'well performed' (A). However, the majority of the reports, $58 \%(n=14)$, were 'generally satisfactory' (B), and $8 \%(n=2)$ were graded as 'just satisfactory' (C) despite omissions and/or inadequacies. The remaining $8 \%(n=2)$ of the reports were graded as 'just unsatisfactory' (D) because of omissions and/or inadequacies. None of the reports obtained an E (unsatisfactory) or F (very unsatisfactory) overall grading.

Figure 3 provides a summary of the quality review results for the different review areas. The best performance was achieved in Review Area 4 (Presentation and communication) with all of the reports being satisfactory (A-C). This was followed by Review Area 1 (Description of project and environment) and Review Area 3 (Alternatives and mitigation) with $96 \%$ satisfactory. However, for Review Area 1, 88\% of the reports were graded as good (A-B grades), compared with $75 \%$ for Review Area 3. The weakest performance was in Review Area 2 (Impact identification and evaluation), which had the lowest frequency of satisfactory grades, with $88 \%$ of the reports achieving a $\mathrm{C}$ or higher.

\section{Review area 1: Description of the project and the environment}

The analysis (Table 3) suggests three main conclusions: 
TABLE 3: Summary of results: Overall grades, review areas and review categories $(n=24)$. Summary of all review areas, categories and sub-categories

\begin{tabular}{|c|c|c|c|c|c|}
\hline \multicolumn{2}{|c|}{ A-C Satisfactory } & \multicolumn{2}{|c|}{ D-F Unsatisfactory } & \multicolumn{2}{|c|}{ N/A Not Applicable } \\
\hline$\%$ & $n$ & $\%$ & $n$ & $\%$ & $n$ \\
\hline 92 & 22 & 8 & 2 & 0 & - \\
\hline 96 & 23 & 4 & 1 & 0 & - \\
\hline 96 & 23 & 4 & 1 & 0 & - \\
\hline 96 & 23 & 4 & 1 & 0 & - \\
\hline 100 & 24 & 0 & - & 0 & - \\
\hline 83 & 20 & 17 & 4 & 0 & - \\
\hline 8 & 2 & 0 & - & 92 & 22 \\
\hline 62 & 15 & 38 & 9 & 0 & - \\
\hline 100 & 24 & 0 & - & 0 & - \\
\hline 54 & 13 & 46 & 11 & 0 & - \\
\hline 88 & 21 & 12 & 3 & 0 & - \\
\hline 100 & 24 & 0 & - & 0 & - \\
\hline 100 & 24 & 0 & - & 0 & - \\
\hline 50 & 12 & 50 & 12 & 0 & - \\
\hline 79 & 19 & 21 & 5 & 0 & - \\
\hline 88 & 21 & 12 & 3 & 0 & - \\
\hline 67 & 16 & 33 & 8 & 0 & - \\
\hline 75 & 18 & 25 & 6 & 0 & - \\
\hline 88 & 21 & 12 & 3 & 0 & - \\
\hline 46 & 11 & 54 & 13 & 0 & - \\
\hline 100 & 24 & 0 & - & 0 & - \\
\hline 100 & 24 & 0 & - & 0 & - \\
\hline 96 & 23 & 4 & 1 & 0 & - \\
\hline 100 & 24 & 0 & - & 0 & - \\
\hline 100 & 24 & 0 & - & 0 & - \\
\hline 100 & 24 & 0 & - & 0 & - \\
\hline 100 & 24 & 0 & - & 0 & - \\
\hline 88 & 21 & 12 & 3 & 0 & - \\
\hline 96 & 23 & 4 & 1 & 0 & - \\
\hline 96 & 23 & 4 & 1 & 0 & - \\
\hline 92 & 22 & 8 & 2 & 0 & - \\
\hline 88 & 21 & 12 & 3 & 0 & - \\
\hline 96 & 23 & 4 & 1 & 0 & - \\
\hline 92 & 22 & 8 & 2 & 0 & - \\
\hline 96 & 23 & 4 & 1 & 0 & - \\
\hline 84 & 20 & 12 & 3 & 0 & - \\
\hline 96 & 23 & 4 & 1 & 0 & - \\
\hline 96 & 23 & 0 & - & 4 & 1 \\
\hline 96 & 23 & 0 & - & 4 & 1 \\
\hline 96 & 23 & 4 & 1 & 0 & - \\
\hline 79 & 19 & 21 & 5 & 0 & - \\
\hline 84 & 20 & 17 & 4 & 0 & - \\
\hline 79 & 19 & 21 & 5 & 0 & - \\
\hline 54 & 13 & 46 & 11 & 0 & - \\
\hline 88 & 21 & 12 & 3 & 0 & - \\
\hline 92 & 22 & 8 & 2 & 0 & - \\
\hline 58 & 14 & 42 & 10 & 0 & - \\
\hline 84 & 20 & 17 & 4 & 0 & - \\
\hline 96 & 23 & 4 & 1 & 0 & - \\
\hline 92 & 22 & 8 & 2 & 0 & - \\
\hline 75 & 18 & 8 & 2 & 17 & 4 \\
\hline 92 & 22 & 8 & 2 & 0 & - \\
\hline 92 & 22 & 8 & 2 & 0 & - \\
\hline 88 & 21 & 8 & 2 & 4 & 1 \\
\hline 96 & 23 & 4 & 1 & 0 & - \\
\hline 96 & 23 & 4 & 1 & 0 & - \\
\hline 96 & 23 & 4 & 1 & 0 & - \\
\hline 96 & 23 & 4 & 1 & 0 & - \\
\hline
\end{tabular}

\section{Overall grade report as a whole}

1 Description of project and environment

1.1 Description of the development

1.1.1 Purpose and objectives

1.1.2 Design and size

1.1.3 Presence and appearance of completed development

1.1.4 Nature of production processes

1.1.5 Nature and quantities of raw materials

1.1.6 Identification of applicant

1.1.7 Details of EAP to carry out assessment

1.2 Site description

1.2.1 Area of development site

1.2.2 Demarcation of land use areas

1.2.3 Duration of different phases

1.2.4 Number of workers and/or visitors

1.2.5 Means of transporting raw materials, products and quantities

1.3 Waste

1.3.1 Types and quantities of wastes

1.3.2 Treatment, disposal and disposal routes

1.3.3 Methods of obtaining quantity of wastes

1.4 Environmental description

1.4.1 Area to be affected by development

1.4.2 Effects occurring away from immediate affected environment

1.5 Baseline conditions

1.5.1 Important components of the affected environment

1.5.2 Existing data sources

1.5.3 Local land use plans, policies consulted

2 Impact identification and evaluation

2.1 Definition of impacts

2.1.1 All possible effects on environment

2.1.2 Interaction of effects

2.1.3 Impacts from non-standard operating procedure

2.1.4 Impacts from deviation from base-line conditions

2.2 Identification of impacts

2.2.1 Impacts identification methodology

2.2.2 Impact identification method used

2.3 Scoping

2.3.1 Contact general public and special interest groups

2.3.2 Collect opinions and concerns of I\&APS

2.3.3 Key impacts

2.4 Prediction of impact magnitude

2.4.1 Data to estimate magnitude of main impacts

2.4.2 Methods used to predict impact magnitude

2.4.3 Predictions of impact in measurable quantities

2.5 Assessment of impact significance

2.5.1 Significance of impact on affected community and society in general

2.5.2 Significance in terms of national and international quality standards

2.5.3 Justification of proposed methods of assessing significance

\section{Alternatives and mitigation}

3.1 Alternatives

3.1.1 Description of alternative sites

3.1.2 Description of alternative processes, design and operating conditions

3.1.3 For severe adverse impacts rejected alternative identified

3.1.4 Comparative assessment of all alternatives identified

3.2 Scope and effectiveness of mitigation measures

3.2.1 Consider mitigation of all significant adverse impacts

3.2.2 Mitigation measures

3.2.3 Extent of effectiveness of mitigation when implemented 
TABLE 3 (Continues...): Summary of results: Overall grades, review areas and review categories $(n=24)$. Summary of all review areas, categories and sub-categories

3.3 Commitment of mitigation

3.3.1 Record of commitment to mitigation measures

3.3.2 Monitoring arrangements

4 Presentation and Communication

4.1 Layout of the report

4.1.1 Introduction

4.1.2 Information logically arranged

4.1.3 Chapter summaries

4.1.4 External sources acknowledged

4.2 Presentation

4.2.1 Presentation of information

4.2.2 Technical terms, acronyms, initials defined

4.2.3 Statement presented as an integrated whole

4.3 Emphasis

4.3.1 Emphasis to potentially severe impacts

4.3.2 Statement must be unbiased

4.3.3 Opinion as to whether activity should/should not be authorised

4.4 Non- technical summary

4.4.1 Non-technical summary of main findings \& conclusions

4.4.2 Summary must cover all main issues

EAP, environmental assessment practitioner; I\&AP, interested and affected parties.

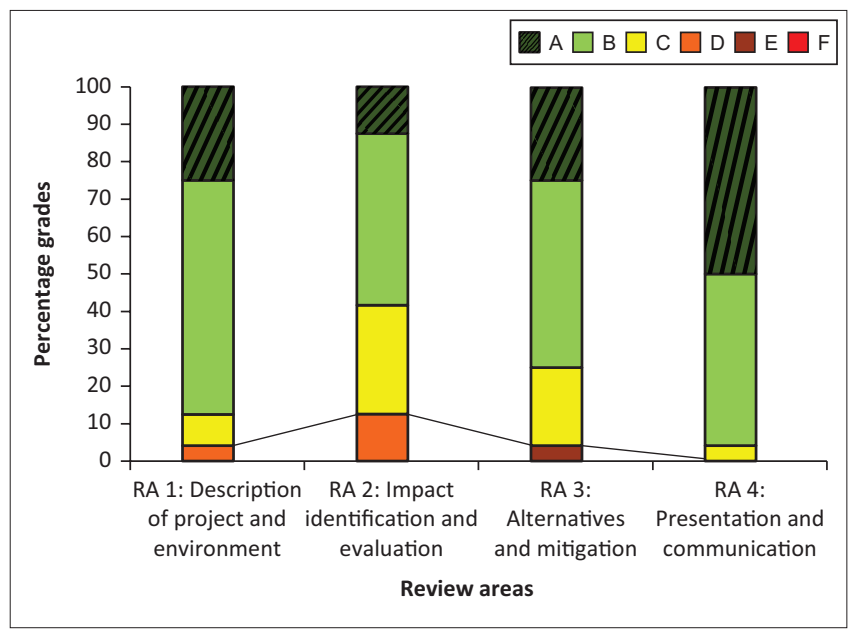

RA, review area.

Note: The black line indicates the critical boundary between 'satisfactory' $(\mathrm{A}-\mathrm{C})$ above and 'unsatisfactory' (D-F) below the line.

FIGURE 3: Grades for review areas of the sample of Environmental Impact Assessment reports in national parks.

- Overall, projects were well described in the EIA reports. This could be expected for developments in national parks because of the national and even international interest in and importance of these areas. This requires the EIA report to accurately communicate the development proposal to well-informed, interested and affected parties. Moreover, the types of developments such as visitor facilities, accommodation and access gates are generally not complex developments per se and are easily described. Conversely, other research has shown that project descriptions are weaker for more complex and large-scale developments such as those related to mining (Sandham et al. 2008a), explosives manufacturing (Sandham et al. 2013b) and large developments impacting on wetlands (Sandham et al. 2008b).

- The description of waste-related aspects was often unsatisfactorily dealt with in the EIA reports, with only $46 \%$ of the reports being satisfactory (A-C) in terms of sub-category 1.3.3. The analysis found weak performance with respect to the description of the types and quantities of waste, treatment, disposal and disposal routes, and description of methods to obtain types and quantities of waste. These results suggest that EIAs for national parks need to significantly strengthen the consideration of waste-related aspects, in order to align with international trends of emphasising and promoting best practice waste management in protected areas (Dunjić et al. 2017; Hockings et al. 2006). Failing in this area could result in omitting waste-related pollution impacts, which must be a critical consideration for any development in a protected area, particularly in national parks. MorrisonSaunders et al. (2019) showed that waste management ranks highly in terms of visitor expectations in the Kruger National Park. Properly dealing with waste management should therefore underpin developmental thinking for protected areas. It is worth noting that dealing with waste also performed poorly in EIA report quality in other sectors (see, e.g., Sandham et al. 2013a, 2013b).

- The environment to be affected and the baseline were generally well described. This is not surprising for EIAs in national parks, especially in the South African context, in which there is a long history of generating scientific data and knowledge to inform conservation management. National parks in South Africa are therefore data rich in terms of environmental and baseline data. 


\section{Review area 2: Impact identification and evaluation}

Based on the quality evaluation results, the following conclusions are made:

- Impact identification and scoping were generally well conducted. This could most likely be attributed to the perceived high profile and sensitive nature of developments in national parks, resulting in high levels of public interest and participation. This, combined with the availability of good quality data and information, seems to result in good quality impact identification and scoping, which is a typical for South African EIA report quality, as public participation is not always well conducted and project impacts are not always well scoped (Kidd et al. 2018).

- Significance prediction and assessment scored the lowest of the five sub-categories in Review Area 2, notwithstanding that quality was found to be relatively high when compared to the more general performance with respect to impact significance in South Africa (see Kidd et al. 2018; Sandham et al. 2013a). Therefore, dealing with the prediction of impact magnitude, data to estimate the magnitude of main impacts and methods used to predict impact magnitude were generally satisfactory. Moreover, the assessment of impact significance on affected communities and society in general and the justification of proposed methods of assessing significance were also satisfactory. However, two sub-categories scored significantly lower. Subcategory 2.4.3 dealing with the predictions of impact in measurable quantities achieved a C score for $54 \%$ of the reports, which highlights the subjective nature of significance ratings and the difficulties in providing quantitative justification for such ratings (Ehrlich \& Ross 2015). Furthermore, sub-category 2.5.2 dealing with significance in relation to national and international quality standards produced a $\mathrm{C}$ grade for more than half (58\%) of the reports. This may be attributed to the fact that such standards do not always exist, especially for more subjective aspects such as aesthetics, visual, heritage, sense of place and social impacts.

\section{Review area 3: Alternatives and mitigation}

Analysis of the review grades lead to the following conclusions:

- Alternatives were generally well described and considered. Although the description of alternative sites in sub-category 3.1.1 had the lowest satisfactory score of the research area, it still achieved a $75 \%$ satisfactory rating overall. The location of developments in national parks is a critical consideration from a mitigation perspective, and related aspects of aesthetics, architecture and building design are highly rated considerations of visitors (Morrison-Saunders et al. 2019) as well as being important for place attachment (Douglas et al. 2019). Therefore, this result is encouraging. Ideally, the location for infrastructure development should be guided by strong strategic planning, promoting the location of development preferably outside of or in buffer areas surrounding parks. Furthermore, the research showed that architectural design alternatives were generally well considered for tourist facilities, accommodation and access gate developments, which supports attempts to mitigate aesthetic and sense of place impacts.

- Mitigation was generally dealt with satisfactorily. In the context of national parks, all impacts are potentially significant, making the identification and implementation of effective mitigation measures particularly important. Moreover, continual monitoring is critical to be able to gauge the effectiveness of mitigation measures over time. The commitment to the implementation of mitigation measures was rated high, which is to be expected, especially in cases where SANParks was the proponent. Public interest also most likely drives mitigation performance in national parks.

\section{Review area 4: Presentation and communication of results}

The communication of EIA information in an accessible format to stakeholders and decision-makers is a critical component of a good quality EIA report. All but one report scored satisfactorily in all categories in this review area, which can be explained by the following: rigorous public scrutiny, the oversight role by SANParks and the quality of available baseline data and information (see Review Area 1). These results suggest that the high quality of the report presentation and communication should place the competent authority in a position to digest, interpret and consider the content towards making an informed and justified decision.

\section{Temporal trends in Environmental Impact Assessment report quality}

In terms of EIAs for national parks, Figure 4 shows that four out of six of the reports for the ECA 1997 regime were graded as satisfactory $(\mathrm{A}-\mathrm{C})$, while all of the EIA reports under the other regimes were found to be satisfactory. Moreover, four of the six ECA 1997 reports obtained a $B$ grading (generally satisfactory) and the remaining two

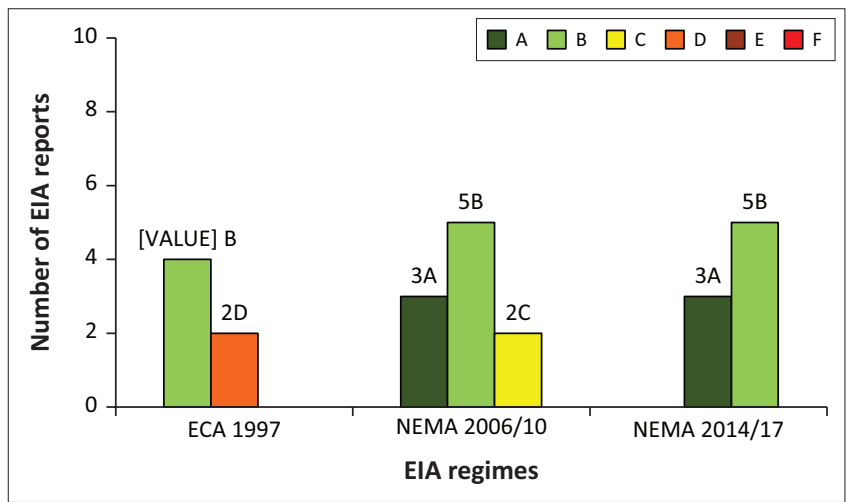

ECA, Environment Conservation Act; NEMA, National Environmental Management Act; EIA Environmental Impact Assessment.

FIGURE 4: Overall quality across Environmental Impact Assessment regimes. 
were graded as 'just unsatisfactory' (D). In the NEMA 2006/10 sample, three reports were 'well performed' (A), five were 'generally satisfactory' and two were graded as 'just satisfactory'(C). In the NEMA 2014/17 sample, three reports were graded as 'well performed' (A) and the remaining five were graded as 'generally satisfactory' (B). In comparison to the ECA 1997 regime, the NEMA regimes (2006/10 and 2014/17) achieved a higher percentage of satisfactory grades, as well as an increase in A and B grades.

Therefore, an increase in overall report quality is noticeable from the ECA regime to the NEMA regimes. Comparing the NEMA regimes, an increase in overall report quality is also observed between the NEMA 2006/10 regime and the NEMA 2014/17 regime, with the NEMA 2006/10 regime achieving two C grades, while the NEMA 2014/17 co-regime only achieved A and B grades.

It is encouraging that EIA report quality for developments in national parks is increasing over time, in contrast to the negative trend identified by Sandham et al. (2013a) in comparing report quality from ECA to NEMA 2006.

\section{Conclusion and recommendations}

This research aimed, for the first time, to determine the quality of EIA reports for a selected sample of developments in SANParks. An adapted version of the well-known Lee and Colley EIA report quality review package (Sandham et al. 2013a) was applied to a sample of 24 EIA reports. Overall, the EIA report quality for developments in national parks was high, which is encouraging. However, certain weaknesses were still evident, especially in relation to the consideration of waste and, to a lesser extent, in dealing with significance and mitigation. The overall good quality results most likely are indicative of certain positive key underlying inputs to the EIA process such as: a strong oversight role by the environmental authority and SANParks, quality of data and information, meaningful public interest and participation and EIA practitioner competency, but further research is needed to test this hypothesis.

Nevertheless, despite these positive results, there are still several cautionary aspects to consider given the methodology and the quality review package applied. While the use of the particular review package is fully justified as it allowed for comparative analysis with previous research, it is also limited in terms of its lack of a sector-specific focus. A protected area sector-specific quality review package would potentially include certain important aspects not addressed by this research. For example, consideration of context in the review package applied is limited to one sub-category (1.5.3) specifically focused on alignment with local land-use plans and policies, which does not explicitly reflect the strategic conservation context or other strategic objectives relevant to tourism in protected areas, such as alignment with responsible tourism practices (Pope et al. 2019). The strategic context for national parks is critical to set cumulative limits and thresholds for consideration of significance in relation to, for example, expanding the number of beds, day visitors, vehicles and services infrastructure. An emphasis on the strategic context would also allow consideration of cumulative impacts and the extent to which aspects such as climate and land use change have been considered in EIA. It is therefore recommended that a protected area-specific review package should include additional sub-categories reflecting other important components of the strategic context for development in protected areas.

In view of the weak performance around waste, whilst a revised package might include waste as a separate review area, the results suggest a pressing need for capacity development in terms of waste management in national parks. This assumes that quality grades are poor because of a lack of understanding of how best to manage waste, rather than any other explanation, although this assumption is untested. In South Africa, which is a water-stressed country, more emphasis might also be required specifically in relation to water use impacts and mitigation. Ideally, the sector-specific quality review package should be designed to still allow for comparison to other report quality research findings.

Ultimately, good EIA report quality could significantly support the potential of EIA to contribute to informed decision-making for developments in national parks. With the expected increase in development pressure on national parks, EIA is therefore well positioned to continue to inform development decisions in national parks towards more sustainable outcomes.

\section{Acknowledgements}

The contributions of anonymous referees are gratefully acknowledged.

\section{Competing interests}

The authors have declared that no competing interests exist.

\section{Authors' contributions}

L.A.S. and C.H. conceptualised the project and were responsible for the data collection, analysis and interpretation. L.A.S., F.P.R., A.M.-S., A.J.B., J.P. and R.C.A. drafted and critically revised the manuscript for important intellectual content and approved the final version to be published.

\section{Funding information}

This research received no specific grant from any funding agency in the public, commercial or not-for-profit sectors.

\section{Data availability statement}

Data sharing is not applicable to this article as no new data were created or analysed in this study. 


\section{Disclaimer}

The views and opinions expressed in this article are those of the authors and do not necessarily reflect the official policy or position of any affiliated agency of the authors.

\section{References}

Alberts, R., Retief, F., Roos, C., Cilliers, D. \& Arakele, M., 2020, 'Re-thinking the fundamentals of EIA through the identification of key assumptions for evaluation', Impact Assessment and Project Appraisal 38(3), 205-213. https://doi.org/10.108 0/14615517.2019.1676069

Arrow, K.A., Bolin, B., Costanza, R., Dasgupta, P., Folke, C., Holling, C.S. et al., 1995 'Economic growth, carrying capacity, and the environment', Science 268(1) 'Economic 521.

Barker, A. \& Jones, C., 2013, 'A critique of the performance of EIA within the offshore oil and gas sector', Environmental Impact Assessment Review 43, 31-39.

Bond, A., Pope, J., Morrison-Saunders, A. \& Retief, F., 2016, 'A game theory perspective on environmental assessment: What games are played and what does this tell us about decision making rationality and legitimacy?', Environmental Impact Assessment Review 57(1), 187-194. https://doi.org/10.1016/j.eiar.2016.01.002

Bond, A., Pope, J., Retief, F., Morrison-Saunders, A., Fundings land, M. \& Hauptfleisch M., 2020, 'Explaining the political nature of Environmental Impact Assessment (EIA): A neo-Gramscian perspective', Journal of Cleaner Production 244(1) 118694. https://doi.org/10.1016/j.jclepro.2019.118694

Bond, A., Retief, F., Cave, B., Fundings land, M., Duinker, P.N., Verheem, R. et al., 2018 'A contribution to the conceptualisation of quality in impact assessment' Environmental Impact Assessment Review 68(1), 49-58. https://doi.org/10.1016/j. eiar.2017.10.006

Boshoff, D.S., 2019, 'Of smoke and mirrors: (Mis)Communicating EIA results of solar energy projects in South Africa', Journal of Environmental Assessment Policy and Management 21(3), 1950014. https://doi.org/10.1142/S1464333219500145

Canelas, L., Almansa, P., Merchan, M. \& Cifuentes, P., 2005, 'Quality of environmental impact statements in Portugal and Spain', Environmental Impact Assessment Review 25(3), 217-225.

Cashmore, M., Christophilopoulos, E. \& Cobb, D., 2002, 'An Evaluation of the Quality of Environmental Impact Statements in Thessaloniki, Greece", Journal of Environmental Assessment Policy and Management 4(4), 371-395.

Christensen, P., Kørnøv, L. \& Nielsen, E.H., 2005, 'EIA as regulation: Does it work?', Journal of Environmental Planning and Management 48(3), 393-412. https://doi. org/10.1080/09640560500067491

Cilliers, D., Van Staden, I., Roos, C., Alberts, R. \& Retief, F., 2020, 'The perceived benefits of EIA for government: A regulators perspective', Impact Assessment and Project Appraisal 38(5). https://doi.org/10.1080/14615517.2020.1734403

De Witt, L., Van Der Merwe, P. \&Saayman, M., 2014, 'Critical ecotourism factors applicable to national parks: A visitor perspective', Tourism Review International 17(3), 179-194.

Douglas, A., Wessels, J-A., Pope, J., Morrison-Saunders, A. \&Hughes, M., 2019 'Measuring Kruger visitors' place attachment to specific camps', KOEDOE 61(1), a159, 1-11. https://doi.org/10.4102/koedoe.v61i1.1559

Dunjić, J., Stojanović, V., Solarević, M. \& Kicošev, V., 2017, 'Sustainable waste management in protected areas of Vojvodina', New Spaces in Cultural Tourism. Conference proceedings: CTTH 2017, Serbia, Novi Sad, September 1-2, 2017.

Ehrlich, A. \& Ross, W., 2015, 'The significance spectrum and EIA significance determinations', Impact Assessment and Project Appraisal 33(2), 87-97. https:// doi.org/10.1080/14615517.2014.981023

Hallatt, T., Retief, F. \&Sandham, L.A., 2015, 'A critical evaluation of the quality of biodiversity inputs to EIA in areas with high biodiversity value - Experience from the Cape Floristic Region, South Africa', Journal of Environmental Assessment the Cape Floristic Region, South Africa',
Policy and Management17(3), 1550025.

Hockings, M., Stolton, S., Leverington, F., Dudley, N. \& Courrau, J., 2006, Evaluating effectiveness: A framework for assessing management effectiveness of protected areas, 2 nd edn., IUCN, Gland.

International Association for Impact Assessment and Institute of Environmental Assessment (IAIA), 1999, Principles of Environmental Impact Assessment Best Practice, viewed 13 December 2018, from http://iaia.org/publicdocuments/ special-publications/Principles\%20of\%20lA web.pdf

Jalava, K., Pasanen, S., Saalasti, M. \& Kuitunen, M., 2010, 'Quality of Environmental Impact Assessment: Finnish EISs and the opinions of EIA professionals', Impact Assessment Project Appraisal 28(1), 15-27. https://doi.org/10.3152/ $146155110 \times 488826$
Kidd, M., Retief, F. \& Alberts, R., 2018, 'Integrated environmental assessment and management', in $\mathrm{H}$. Strydom, N. King \& F. Retief (eds.), Fuggle and Rabie's management', in $\mathrm{H}$. Strydom, N. King \& $\mathrm{F}$. Retief (eds.), Fuggle and Rabie's
environmental management in South Africa, pp. 1213-1275, Juta, Cape Town.

Lee, N., Colley, R., Bonde, J. \& Simpson, J., 1999, Reviewing the quality of environmental statements and environmental appraisals, Occasional paper number 55, EIA Centre, Department of Planning and Landscape, University of Manchester, Manchester.

McGrath, C. \& Bond, A., 1997, 'The quality of environmental impact statements: a review of those submitted in Cork, Eire from 1988-1993', Project Appraisal 12(1), 43-52.

Morgan, R.K., 2012, 'Environmental Impact Assessment: The state of the art', Impact Assessment and Project Appraisal 30(1), 5-14. https://doi.org/10.1080/1461551 7.2012.661557

Morrison-Saunders, A., Hughes, M., Pope, J., Douglas, A. \& Wessels, J-A., 2019 'Understanding visitor expectations for responsible tourism in an iconic national park: Differences between local and international visitors', Journal of Ecotourism 18(3), 284-294. https://doi.org/10.1080/14724049.2019.1567740

Pope, J., Bond, A., Morrison-Saunders, A., Cameron, C. \& Retief, F., 2018, 'Are current effectiveness criteria fit for purpose? Using a controversial strategic assessment as a test case', Environmental Impact Assessment Review 70(1), 34-44. https://doi. org/10.1016/j.eiar.2018.01.004

Pope, J., Wessels, J.A., Douglas, A., Hughes, M. \& Morrison-Saunders, A., 2019, 'The potential contribution of Environmental Impact Assessment (EIA) to responsible tourism: The case of the Kruger National Park', Tourism Management Perspectives 32(1), 100557. https://doi.org/10.1016/j.tmp.2019.100557

Põder, T. \& Lukki, T., 2011, 'A critical review of checklist-based evaluation of environmental impact statements', Impact Assessment and Project Appraisal, 29(1), 27-38.

Retief, F., 2010, 'The evolution of environmental assessment debates - Critical perspectives from South Africa', Journal of Environmental Assessment Policy and Management 12(4), 1-23. https://doi.org/10.1142/S146433321000370X

Roos, C., Cilliers, D., Retief, F., Alberts, R. \& Bond A., 2020, 'Regulators' perceptions of Environmental Impact Assessment (EIA) benefits in a sustainable development context', Environmental Impact Assessment Review 81(1), 106360. https://doi. context', Environmental Impact
org/10.1016/j.eiar.2019.106360

Sandham, L.A., Carrol, T. \& Retief, F., 2010, 'The contribution of Environmental Impact Assessment (EIA) to decision making for biological pest control in South Africa The case of Lantana camara', Biological Control 55(2), 141-149. https://doi. org/10.1016/j.biocontrol.2009.12.010

Sandham, L.A., Hoffmann, A.R. \& Retief, F.P., 2008a, 'Reflections on the quality of mining ElA reports in South Africa', The Journal of the Southern African Institute of Mining and Metallurgy 108(1), 701-706.

Sandham, L.A., Moloto, M. \& Retief, F., 2008b, 'The quality of Environmental Impact Assessment reports for projects with the potential of affecting wetlands', Water SA 34(2),155-162.

Sandham, L.A. \& Pretorius, H.M., 2008, 'A review of EIA report quality in the North West province of South Africa', Environmental Impact Assessment Review 28(4-5), 229-240. https://doi.org/10.1016/j.eiar.2007.07.002

Sandham, L.A., Van Heerden, A.J., Jones, C.E., Retief, F.P. \& Morrison-Saunders, A.N., 2013a, 'Does enhanced regulation improve ElA report quality? Lessons from South Africa', Environmental Impact Assessment Review 38(1), 155-162. https:// doi.org/10.1016/j.eiar.2012.08.001

Sandham, L.A., Van Der Vyver, F. \& Retief, F.P., 2013b, 'The performance of Environmental Impact Assessment in the explosives manufacturing industry in South Africa', Journal of Environmental Assessment Policy and Management 15(3), 1350013. https://doi.org/10.1142/S1464333213500130

Steffen, W., Richardson, K., Rockström., Cornell, S.E., Fetzer, I., Bennett, E.M. et al. 2015, 'Planetary boundaries: Guiding human development on a changing planet', Science 347(6223), 1259855. https://doi.org/10.1126/science.1259855

Swanepoel, F., Retief, F., Bond, A., Pope, J., Morrison-Saunders, A., Hauptfleisch, M. et al., 2019, 'Evaluating the quality of biodiversity inputs to Environmental Impact
Assessments (EIA) in areas with high biodiversity value', Journal of Environmental Assessments (EIA) in areas with high biodiversity value', Journal of Environmental Assessment,
3219500091

Swemmer, L.K. \&Taljaard, S., 2011, 'SANParks, people and adaptive management: Understanding a diverse field of practice during changing times', KOEDOE 53(2), 1-7. https://doi.org/10.4102/koedoe.v53i2.1017

Wylie, D.K., Bhattacharjee, S. \&Rampedi, I.T., 2018, 'Evaluating the quality of environmental impact reporting for proposed tourism-related infrastructure in the protected areas of South Africa: A case study on selected EIA reports', African Journal of Hospitality, Tourism and Leisure 7(3), 1-14.

Yang, T., 2019, 'The emergence of the Environmental Impact Assessment duty as a global legal norm and general principle of law', Hastings Law Journal 70(2), 525-572.

Yin, R., 2003, Case study research: Design and methods, 3rd edn., Applied Social Research Methods Series, vol. 5, Sage, London. 